\title{
A 5-Year Review of Hospital Costs and Reimbursement in the Surgical Management of Degenerative Spondylolisthesis
}

\author{
KEITH W. LYONS, MD, CHRISTIAN M. KLARE, MD, SAMUEL T. KUNKEL, MD, MS, JASON R. LEMIRE, \\ MPH FACHE, ,MIKE BAO, BS, KEVIN J. MCGUIRE MD, MS, ADAM M. PEARSON MD, MS, WILLIAM A. \\ ABDU MD, MS \\ Dartmouth-Hitchcock Medical Center, Department of Orthopaedics, Lebanon, New Hampshire
}

\begin{abstract}
Background: To evaluate charges, expenses, reimbursement, and hospital margins with noninstrumented posterolateral fusion in situ (PLF), posterolateral fusion with pedicle screws (PPS), and PPS with interbody device (PLIF) in degenerative spondylolisthesis with spinal stenosis.

Methods: A retrospective chart review was performed from 2010 to 2014 based on ICD-9 diagnoses of degenerative spondylolisthesis with spinal stenosis in patients undergoing single-level fusions. All charges, expenses, reimbursement, and margins were obtained through financial auditing. A multivariate linear regression model was used to compare demographics, charges, etc. A 1-way analysis of variance with Tukey post hoc analysis was used to analyze reimbursements and margins based upon insurances.

Results: Two hundred thirty-three patients met inclusion criteria. The overall charges and expenses for PLF were significantly less compared to both types of instrumented fusions $(P<.0001)$. Medicare and private insurance were the most common insurance types; Medicare and private insurance mean reimbursements for PLF were $\$ 36,903$ and \$47,086, respectively; for PPS, \$37,450 and \$53,851, and for PLIF \$40,171 and \$51,640. Hospital margins for PPS and PLIF in Medicaid patients were negative $(-\$ 3,702$ and $-\$ 6,456)$. Hospital margins were largest for both worker's compensation and private insurance patients in all fusion groups. Hospital margins with Medicare for PLF, PPS, and PLIF were \$24,347, \$19,205, and \$23,046, respectively. Hospital margins for private insurance for PLF, PPS, and PLIF were $\$ 37,569, \$ 36,834$, and $\$ 33,134$, respectively.

Conclusions: As more instrumentation is used, the more it costs both the hospital and the insurance companies; hospital margins did not increase correspondingly.

Clinical Relevance: Improved understanding of related costs and margins associated with lumbar fusions to help transition to more cost effective spine centers.

Lumbar Spine

Keywords: degenerative spondylolisthesis, reimbursement, hospital cost
\end{abstract}

\section{INTRODUCTION}

Degenerative spondylolisthesis (DS) is a common condition for which surgery is performed in the United States. It typically occurs in the sixth decade of life and more commonly affects women. Patients usually present with a combination of symptoms of neurogenic claudication, radiculopathy, or associated back pain. ${ }^{1}$ There is some degree of variability in the surgical treatment of DS with spinal stenosis. The Spine Patient Outcomes Research Trial (SPORT) demonstrated that in patients with DS and associated spinal stenosis, those treated surgically had greater improvement in pain and function at 2, 4, and 8 years in comparison to patients treated nonoperatively. ${ }^{2,3}$ A subgroup analysis of the SPORT trial found that DS patients treated with noninstrumented posterolateral fusion in situ (PLF), posterolateral instrumented fusion with pedicle screws (PPS), or PPS plus interbody fusion (PLIF) had no significant difference in outcomes at 4 and 8 years. ${ }^{4}$

From 1998 to 2008, the frequency with which spinal fusions were performed increased at a higher rate compared to other notable inpatient procedures. ${ }^{5}$ There is significant variation in the treatment of patients with lumbar spine pathology across the United States. ${ }^{6}$ At the same time, the number of physicians performing these procedures has in- 
creased, as has the use of allografts, interbody devices, and hardware in spine surgery. ${ }^{7}$ From 2004 to 2009 , it was also shown that the costs of implantable devices rose $4.3 \%$ per year. ${ }^{8}$ In 1992 , the costs of lumbar spinal fusions accounted for $14 \%$ of total spending for spine surgery. By 2003 , that had increased to $47 \%$ of spending for spine surgery. ${ }^{5}$

The public is viewing spinal surgery rates and the use of fusions with greater scrutiny than they have in the past. ${ }^{9,10}$ There has been an increasing interest in improving value in healthcare with payers and providers, and looking for ways to decrease the expanding costs of healthcare. The changes in Medicare reimbursements are a testament to this evolution in medicine.

In many payment models, physicians are reimbursed based upon Medicare's physician fee schedule, which determines a fee for each service dependent on its relative value units (RVUs), which are based upon the scale of resources required to provide each service. In general, those services that require greater resources and time per physician have a greater associated RVU. As expected, when procedures require implants, hardware, or fusion, the RVUs can increase.

The aim of our study was to evaluate hospitalrelated economics of surgical management of DS. Specifically, we analyzed hospital charges, reimbursement, expenses, and overall hospital margins.

This study was performed at Dartmouth-Hitchcock Medical Center's Spine Center. DartmouthHitchcock Medical Center's Spine Center has a multidisciplinary approach to patients treated with spine conditions. The Spine Center includes orthopedic surgeons, neurosurgeons, pain specialists, and physical therapists.

\section{METHODS}

After institutional review board approval was obtained, a retrospective chart review and corresponding financial audit was performed over a period from 2010 to 2014 at Dartmouth-Hitchcock Medical Center. A patient was deemed eligible for inclusion in the study if they had undergone spinal surgery by an orthopedic surgeon or neurosurgeon and they had International Classification of Diseases Book 9 (ICD-9) codes for spinal stenosis (742.02) and DS $(738.4,756.2)$. The review was therefore based on diagnosis, and then stratified by type of procedure. The procedures performed all included an initial decompressive laminectomy. The procedures then varied in terms of method of fusion. Three fusion methods were analyzed in this study: PLF, PPS, and PLIF. The study included all patients who met the correct diagnosis criteria as mentioned above, and who then went on to have a single-level fusion. Patients who had multilevel fusions were excluded from the study. For each surgery, the total work RVU of each procedure was determined using the procedural codes used for each surgery based on the corresponding Current Procedural Terminology codes used.

Professional and technical charges and expenses were determined through the finance department using all service and procedural billed charges and expenses for each surgery and hospital stay. Professional and technical charges were the amount that the hospital charged (billed) the primary payer (insurance). Professional charges were for the physician's services (anesthesiology, orthopedics, etc). Technical charges were comprised of supplies, facilities, nonphysician medical staff, implants, etc.

The professional and technical expenses were the actual expenses incurred by the hospital; these were the direct costs to the hospital. Again, technical expenses refer to non-physician-related costs (supplies, overhead, implants), whereas professional expenses refer to the physician expenses. Technical expenses were derived from itemized lists for each patient's hospitalization compiled by the hospital's charge master and financial department. These lists included all expenses such as medications, supplies, and implants. The specific costs of supplies and implants were not included in this study as that contains proprietary information and is therefore confidential. Professional expenses are what the hospital had to pay the medical staff (surgeons, anesthesiologists). The reimbursement model at our institution was outside of the scope of this study.

Hospital reimbursement was calculated when factoring in all total charges (professional and technical), contractuals, debt, and charity. In this study, reimbursement reflects overall total reimbursement (physicians and hospital). Hospital margins were then determined when calculating the difference between the hospital reimbursement and total expenses (professional and technical). Primary payer (insurance) data were also provided from the financial audit. Insurance was grouped into 6 categories (Medicaid, Medicare, worker's compensation, private insurance, charity, and self-pay). 
Charges and expenses were then compared to Medicare's Diagnosis-Related Groups 460 and 491 reimbursement.

Additionally, operating room length of time, estimated blood loss, occurrence of incidental durotomy, and length of hospital stay were also evaluated for each procedure. Other demographic data were also collected, including age, sex, body mass index (BMI), American Society of Anesthesiologists (ASA) classification, and smoking status.

In this project, a multivariate linear regression was used to compare charges, reimbursements, expenses, margins, and RVUs among the 3 fusion groups by adjusting a list of covariates including estimated blood loss, operating room time (minutes), sex $(\mathrm{M} / \mathrm{F})$, BMI, smoking history, ASA classification, incidental durotomy, age, length of stay (days), and insurance type. Least square means (LSM) in each group, difference of LSM, its 95\% confidence interval, and adjusted $P$ value by the Scheffe method for multiple comparisons were provided. Two-sided significance level was set at $5 \%$. All analyses were conducted in SAS 9.4 (SAS Institute, Cary, NC). A 1-way analysis of variance (ANOVA) with Tukey post hoc analysis was then used to further break down different reimbursements and margins based upon individual insurance types.

\section{RESULTS}

Two hundred thirty-three patients met inclusion criteria for the study (Table 1). Of those, 106 underwent PLF, 79 underwent PPS, and 48 underwent PLIF. There were no significant differences in distribution of gender, length of stay, ASA classification, BMI, or occurrence of durotomy. There were significant differences between the mean surgical times: PLF had a mean time of 211.22 minutes, PPS was 277.57 minutes, and PLIF was 257.55 minutes $(P<.001)$. Estimated blood loss was also significantly different among the 3 groups: PLF had a mean of $317 \mathrm{~mL}$ blood loss, while PPS was $462 \mathrm{~mL}$, and PLIF was $476 \mathrm{~mL}(P<.001)$.

The different charges, expenses, reimbursements, margins, and net work RVUs are listed in Table 2. The values in Table 2 reflect the LSM from the multivariate model that controlled for insurance type. In terms of technical, professional, and total charges, PLF was less expensive (for the insurance company and/or patient) when compared to both PPS and PLIF $(P<.0001)$. In other words, the hospital billed the insurance companies or patients less for the PLF than for the instrumented fusions. This was due to the combination of both the technical and professional charges. The LSM total charges for PLF, PPS, and PLIF were \$74,650.29, $\$ 93,371.36$ and $\$ 102,766.80$, respectively.

In terms of overall expenses (what the hospital had to spend), PLF was less expensive when compared to both PPS and PLIF $(P<.0001)$. The LSM total expenses for PLF, PPS, and PLIF were $\$ 13,248.10, \$ 18,104.33$, and $\$ 19,740.99$, respectively. Again, expenses refer to what the hospital had to pay or spend for the procedures. This includes both technical and professional expenses.

The LSM total hospital reimbursements (this refers to all reimbursement, including both physician and hospital) for PLF, PPS, and PLIF were $\$ 36,316.97, \$ 40,184.13$, and $\$ 45,399.33$, respectively. Reimbursement for PLF was significantly less compared to PLIF $(P=.03)$. There was no statistical difference when comparing PLF to PPS, or PPS to PLIF.

The hospital margins for the 3 groups were not statistically different when controlling for all variables including insurance type. PLF had a net margin of $\$ 23,068.87$, PPS was $\$ 22,079.80$, and PLIF was $\$ 25,658.34(P=.92, P=.71, P=.49$, respectively). There were significant differences in the mean total work RVUs for each fusion type. The mean work RVUs associated with PLF, PPS, and PLIF were 51.51, 64.32, and 85.09 respectively $(P<.0001)$.

ANOVA was then used to further characterize the differences in hospital reimbursement and hospital margin when looking at the individual insurance types (Medicaid, Medicare, worker's compensation, private insurance, charity, and selfpay).

For PLF (Table 3), ANOVA demonstrated there was significant variation among insurance types for hospital reimbursement $(P=.002)$. The mean reimbursements from Medicaid, Medicare, worker's compensation, private insurance were $\$ 12,687.74$, $\$ 36,903.36, \$ 47,882.70$, and $\$ 47,086.21$, respectively. Hospital reimbursement was significantly higher for Medicare $(P=.003)$, worker's compensation $(P<.001)$, and private insurance $(P<.001)$ compared to Medicaid. Private insurance was significantly higher than Medicare $(P<.001)$. There was no significant difference between Medicare and worker's compensation, or between worker's com- 
Table 1. Characteristics for patients with degenerative spondylolisthesis with spinal stenosis.

\begin{tabular}{|c|c|c|c|c|}
\hline Variables & $\operatorname{PLF}(n=106)$ & PPS $(n=79)$ & PLIF $(n=48)$ & $P$ Value ${ }^{\mathrm{a}}$ \\
\hline Age, mean (SD) & $63.12(13.75)$ & $57.05(12.21)$ & $46.19(12.43)$ & $<.0001$ \\
\hline \multicolumn{5}{|l|}{ Gender } \\
\hline Female, n $(\%)$ & $59(55.66)$ & $42(53.16)$ & $20(41.67)$ & \multirow[t]{2}{*}{.28} \\
\hline Male, n $(\%)$ & $47(44.34)$ & $37(46.84)$ & $28(58.33)$ & \\
\hline \multicolumn{5}{|l|}{ ASA } \\
\hline $1, \mathrm{n}(\%)$ & $9(8.49)$ & $3(3.8)$ & $3(6.25)$ & \multirow[t]{4}{*}{.58} \\
\hline $2, \mathrm{n}(\%)$ & $59(55.66)$ & $48(60.76)$ & $31(64.58)$ & \\
\hline $3, \mathrm{n}(\%)$ & $35(33.02)$ & $28(35.44)$ & $14(29.17)$ & \\
\hline $4, \mathrm{n}(\%)$ & $3(2.83)$ & $0(0)$ & $0(0)$ & \\
\hline BMI, mean (SD) & $29.14(6.67)$ & $30.69(7.1)$ & $30.14(4.71)$ & .26 \\
\hline \multicolumn{5}{|l|}{ Smoking history } \\
\hline No, n $(\%)$ & $62(58.49)$ & $41(51.9)$ & $13(27.08)$ & \multirow[t]{2}{*}{.001} \\
\hline Yes, n $(\%)$ & $44(41.51)$ & $38(48.1)$ & $35(72.92)$ & \\
\hline \multicolumn{5}{|l|}{ Incidental durotomy } \\
\hline No, n $(\%)$ & $100(94.34)$ & $74(93.67)$ & $48(100)$ & \multirow[t]{2}{*}{.23} \\
\hline Yes, n $(\%)$ & $6(5.66)$ & $5(6.33)$ & $0(0)$ & \\
\hline Length of stay, mean days (SD) & $3.16(2.85)$ & $2.99(1.21)$ & $2.83(1.36)$ & .66 \\
\hline \multicolumn{5}{|l|}{ Insurance } \\
\hline Medicaid, n (\%) & $3(2.83)$ & $1(1.27)$ & $5(10.42)$ & \multirow[t]{6}{*}{.004} \\
\hline Medicare, n (\%) & $54(50.94)$ & $29(36.71)$ & $13(27.08)$ & \\
\hline Worker's compensation, n (\%) & $5(4.72)$ & $4(5.06)$ & $7(14.58)$ & \\
\hline Private insurance, $\mathrm{n}(\%)$ & $44(41.51)$ & $44(55.7)$ & $22(45.83)$ & \\
\hline Charity, n $(\%)$ & $0(0)$ & $0(0)$ & $1(2.08)$ & \\
\hline Self-pay, n (\%) & $0(0)$ & $1(1.27)$ & $0(0)$ & \\
\hline
\end{tabular}

Abbreviations: PLF, noninstrumented posterolateral fusion in situ; PPS, posterolateral fusion with pedicle screws; PLIF, PPS with interbody device; ASA, American Society of Anesthesiologists score; BMI, body mass index.

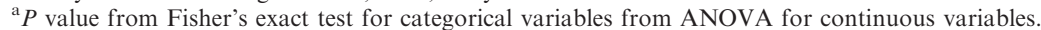

Table 2. Comparison of charges, expenses, reimbursement, margin, and net RVUs for various fusion methods.

\begin{tabular}{|c|c|c|c|c|c|}
\hline & Fusion Type & $\begin{array}{l}\text { Least Square } \\
\text { Mean }^{\mathrm{a}}\end{array}$ & $\begin{array}{c}\text { Fusion } \\
\text { Comparison }\end{array}$ & $\begin{array}{l}\text { Difference of Least Square Mean } \\
\text { (95\% CI) }\end{array}$ & $P$ Value $^{\mathrm{b}}$ \\
\hline \multirow[t]{3}{*}{ Technical charges } & PLF & $\$ 41,700.51$ & PLF versus PPS & $-12432.26(-16796.74,-8067.78)$ & $<.0001$ \\
\hline & PPS & $\$ 54,132.77$ & PLF versus PLIF & $-15063.96(-20619.75,-9508.16)$ & $<.0001$ \\
\hline & PLIF & $\$ 56,764.47$ & PPS versus PLIF & $-2631.69(7956.67,2693.28)$ & .48 \\
\hline \multirow[t]{3}{*}{ Professional charges } & PLF & $\$ 32,949.78$ & PLF versus PPS & $-6288.81(-9428.06,-3149.56)$ & $<.0001$ \\
\hline & PPS & $\$ 39,238.59$ & PLF versus PLIF & $-13052.5(-17048.64,-9056.37)$ & $<.0001$ \\
\hline & PLIF & $\$ 46,002.28$ & PPS versus PLIF & $-6763.69(-10593.8,-2933.58)$ & $<.001$ \\
\hline \multirow[t]{3}{*}{ All charges } & PLF & $\$ 74,065.29$ & PLF versus PPS & $-18421.07(-25125.85,-12316.29)$ & $<.0001$ \\
\hline & PPS & $\$ 93,371.36$ & PLF versus PLIF & $-28116.46(-36269.47,-19963.44)$ & $<.0001$ \\
\hline & PLIF & $\$ 102,766.80$ & PPS versus PLIF & $-9395.39(-17209.67,-1581.1$ & .01 \\
\hline \multirow[t]{3}{*}{ Technical expenses } & PLF & $\$ 7,244.21$ & PLF versus PPS & $-4617.04(-5986.97,-3247.11)$ & $<.0001$ \\
\hline & PPS & $\$ 11,861.25$ & PLF versus PLIF & $-6567.66(-8311.52,-4823.8)$ & $<.0001$ \\
\hline & PLIF & $\$ 13,811.87$ & PPS versus PLIF & $-1850.62(-3622.03,-279.21)$ & .02 \\
\hline \multirow{3}{*}{ Professional expenses } & PLF & $\$ 5,967.80$ & PLF versus PPS & $-232.83(-1081.05,615.39)$ & .8 \\
\hline & PPS & $\$ 6,200.64$ & PLF versus PLIF & $-18.95(-1098.7,1060.8)$ & 1 \\
\hline & PLIF & $\$ 5,986.75$ & PPS versus PLIF & $213.88(-821.01,1248.77)$ & .88 \\
\hline \multirow[t]{3}{*}{ All expenses } & PLF & $\$ 13,248.10$ & PLF versus PPS & $-4856.23(-6874.15,-2838.31)$ & $<.0001$ \\
\hline & PPS & $\$ 18,104.33$ & PLF versus PLIF & $-6492.89(-9061.62,-3924.17)$ & $<.0001$ \\
\hline & PLIF & $\$ 19,740.99$ & PPS versus PLIF & $-1636.67(-4098.67,825.34)$ & .026 \\
\hline \multirow{3}{*}{$\begin{array}{l}\text { Hospital reimbursement } \\
\quad \text { (professional }+ \text { technical) }\end{array}$} & PLF & $\$ 36,316.97$ & PLF versus PPS & $-3867.16(-10579.85,2845.54)$ & .37 \\
\hline & PPS & $\$ 40,184.13$ & PLF versus PLIF & $-9082.36(-17627.33,-537.39)$ & .03 \\
\hline & PLIF & $\$ 45,399.33$ & PPS versus PLIF & $-5215.21(-13405.16,2974.75)$ & .29 \\
\hline \multirow[t]{3}{*}{ Hospital margin } & PLF & $\$ 23,068.87$ & PLF versus PPS & $989.07(-5071.06,7049.2)$ & .92 \\
\hline & PPS & $\$ 22,079.80$ & PLF versus PLIF & $-2589.47(-10303.75,5124.82)$ & .71 \\
\hline & PLIF & $\$ 25,658.34$ & PPS versus PLIF & $-3578.54(-10972.32,3815.25)$ & .49 \\
\hline \multirow[t]{3}{*}{ Net RVUs } & PLF & 51.51 & PLF versus PPS & $-12.81(-17.57,-8.06)$ & $<.0001$ \\
\hline & PPS & 64.32 & PLF versus PLIF & $-33.58(-39.63,-27.52)$ & $<.0001$ \\
\hline & PLIF & 85.09 & PPS versus PLIF & $-20.76(-26.57,-14.96)$ & $<.0001$ \\
\hline
\end{tabular}

Abbreviations: RVU, relative value unit; CI, confidence interval; PLF, noninstrumented posterolateral fusion in situ; PPS, posterolateral fusion with pedicle screws; PLIF, PPS with interbody device.

${ }^{a}$ Least square means estimated from multivariate model.

${ }^{\mathrm{b}} P$ value adjusted by the Scheffe method for multiple comparisons. 
Table 3. Hospital reimbursement and margins for noninstrumented fusion in situ.

\begin{tabular}{|c|c|c|c|c|}
\hline Insurance Type & Mean Reimbursement & Insurance Comparison & Difference of Mean $(95 \% \mathrm{CI})$ & $P$ Value \\
\hline Medicaid (1) & $\$ 12,687.74$ & 1 versus 2 & $\$ 24,215.63(6712.825,41718.43)$ & .003 \\
\hline Medicare (2) & $\$ 36,903.36$ & 1 versus 3 & $\$ 35,398.47(13645.96,56$ 743.94) & 0 \\
\hline Worker's compensation (3) & $\$ 47,882.70$ & 1 versus 4 & $\$ 34,398.47(1679.3,52$ 005.64) & 0 \\
\hline Private insurance (4) & $\$ 47,086.21$ & 2 versus 3 & $\$ 10,979.33(2814.081,24$ 772.75) & .167 \\
\hline Charity (5) & None & 2 versus 4 & $\$ 10,182.84(4190.213,16$ 175.47) & 0 \\
\hline Self-pay (6) & None & 2 versus 4 & $\$-796.4901(-14722.1,13$ 129.12) & .999 \\
\hline Insurance type & Mean Margin & Insurance Comparison & Difference of Mean $(95 \%$ CI) & $P$ Value \\
\hline Medicaid (1) & $\$ 4,127.01$ & 1 versus 2 & $\$ 20,220.48(2368.687,38072.28)$ & .02 \\
\hline Medicare (2) & $\$ 24,347.49$ & 1 versus 3 & $\$ 33,446.27(11467.6,55424.94)$ & .001 \\
\hline Worker's compensation (3) & $\$ 37,573.28$ & 1 versus 4 & $\$ 33,442.75(15484.5,51401)$ & 0 \\
\hline Private insurance (4) & $\$ 37,569.76$ & 2 versus 3 & $\$ 13,228.79(-842.6573,27294.24)$ & .073 \\
\hline Charity (5) & None & 2 versus 4 & $\$ 13,222.27(7110.148,19334.39)$ & 0 \\
\hline Self-pay (6) & None & 2 versus 4 & $\$-3.512386(-14206.8,14$ 199.76) & 1 \\
\hline
\end{tabular}

Abbreviation: CI, confidence interval.

pensation and private insurance. Charity and selfpay were excluded from this as there were none in this group. Hospital margins with Medicaid were significantly lower than Medicare $(P=.02)$, worker's compensation $(P=.001)$, and private insurance $(P<.001)$. Private insurance was also associated with significantly higher hospital margins than Medicare $(P<.001)$. Hospital margins for PLF with Medicaid, Medicare, worker's compensation, and private insurance were $\$ 4,127.01, \$ 24,347.49$, $\$ 37.573 .28$, and $\$ 37,569.76$, respectively.

For the PPS group (Table 4), ANOVA demonstrated there was significant variation among insurance type for hospital reimbursements $(P<.001)$. The mean reimbursements from Medicaid, Medicare, worker's compensation, and pri- vate insurance were $\$ 11,843.71, \$ 37,450.91$, $\$ 65,842.54$, and $\$ 53,851.78$, respectively. Hospital reimbursement was significantly higher for worker's compensation than for Medicaid $(P=.015)$ or Medicare $(P=.006)$. It was also significantly higher for private insurance than for Medicare $(P<.001)$, and higher for self-pay than for Medicaid $(P=.011)$ or Medicare $(P=.032)$. Charity pay was left out of this group as there were none. There was also significant variation among insurance for hospital margins $(P<.001)$. Hospital margins for PLF with Medicaid, Medicare, worker's compensation, and private insurance were $-\$ 3,702.47, \$ 19,205.55$, $\$ 48,569.44$, and $\$ 36,834.93$, respectively. Hospital margins were significantly higher for worker's compensation than for Medicaid $(P=.029)$ and

Table 4. Hospital reimbursement and margins for posterolateral fusion with pedicle screws.

\begin{tabular}{|c|c|c|c|c|}
\hline Insurance Type & Mean Reimbursement & Insurance Comparison & Difference of Mean $(95 \%$ CI) & $P$ Value \\
\hline Medicaid (1) & $\$ 11,843.71$ & 1 versus 2 & $\$ 25,607.2(-16801.63,68016.03)$ & .447 \\
\hline Medicare (2) & $\$ 37,450.91$ & 1 versus 3 & $\$ 53,998.83(7381.263,100616.4)$ & .015 \\
\hline Worker's compensation (3) & $\$ 65,842.54$ & 1 versus 4 & $\$ 42,008.07(-159.1057,85175.25)$ & .051 \\
\hline Private insurance (4) & $\$ 53,851.78$ & 1 versus 6 & $\$ 70,651.15(11684.07,129618.2)$ & .011 \\
\hline Charity (5) & None & 2 versus 3 & $\$ 28,391.63(6152.257,50631.01)$ & .006 \\
\hline \multirow[t]{5}{*}{ Self-pay (6) } & $\$ 82,494.86$ & 2 versus 4 & $\$ 16,400.87(6427.76,26373.99)$ & 0 \\
\hline & & 2 versus 6 & $\$ 45,043.95(-29965.8,9784.277)$ & .54 \\
\hline & & 3 versus 4 & $\$-11,990.76(-33765.8,9784.277)$ & .32 \\
\hline & & 3 versus 6 & $\$ 16,652.32(-29965.25,63269.89)$ & .855 \\
\hline & & 4 versus 6 & $\$ 28,643.08(13524.1,70810.26)$ & .327 \\
\hline Insurance type & Mean Margin & Insurance Comparison & Difference of Mean (95\% CI) & $P$ Value \\
\hline Medicaid (1) & $-\$ 3,702.47$ & 1 versus 2 & $\$ 22,908.02(213.65,67$ 184.68) & 6 \\
\hline Medicare (2) & $\$ 19,205.55$ & 1 versus 3 & $\$ 52,271.91(3601.134,100942.7$ & .029 \\
\hline Worker's compensation (3) & $\$ 48,569.44$ & 1 versus 4 & $\$ 40,537.4(-3486.977,84561.77)$ & .086 \\
\hline Private insurance (4) & $\$ 36,834.93$ & 1 versus 6 & $\$ 69,138.69(7574.484,130702.9)$ & .02 \\
\hline Charity (5) & None & 2 versus 3 & $\$ 29,363.9(6154.017,52582.77)$ & .006 \\
\hline \multirow[t]{5}{*}{ Self-pay (6) } & $\$ 65,436.22$ & 2 versus 4 & $\$ 17,629.38(7217.017,28041.75)$ & 0 \\
\hline & & 2 versus 6 & $\$ 46,230.67(1954.008,90507.34)$ & .036 \\
\hline & & 3 versus 4 & $\$-11,734.51(-34468.6,10999.58)$ & .602 \\
\hline & & 3 versus 6 & $\$ 16,866.78(-31804,65537.55)$ & .868 \\
\hline & & 4 versus 6 & $\$ 28,601.29(-15423.08,72$ 625.67) & .372 \\
\hline
\end{tabular}

Abbreviation: CI, confidence interval. 
Table 5. Hospital reimbursement and margins for posterolateral fusion with pedicle screws and interbody device.

\begin{tabular}{|c|c|c|c|c|}
\hline Insurance Type & Mean Reimbursement & Insurance Comparison & Difference of Mean (95\% CI) & $P$ Value \\
\hline Medicaid (1) & $\$ 13,818.96$ & 1 versus 2 & $\$ 26,352.51(-13767.95,66472.98)$ & .349 \\
\hline Medicare (2) & $\$ 40,171.48$ & 1 versus 3 & $\$ 71,449.1(26807.17,116091)$ & 0 \\
\hline Worker's compensation (3) & $\$ 85,268.07$ & 1 versus 4 & $\$ 37,821.21(49.04229,75$ 593.38) & .05 \\
\hline Private insurance (4) & $\$ 51,640.18$ & 1 versus 5 & $\$-13,184.14(-96701.56,70333.27)$ & .991 \\
\hline Charity (5) & $\$ 634.82$ & 2 versus 3 & $\$ 45,096.59(9354.436,80838.74)$ & .007 \\
\hline \multirow[t]{5}{*}{ Self-pay (6) } & None & 2 versus 4 & $\$ 11,468.7(-15202.18,38139.58)$ & .737 \\
\hline & & 2 versus 5 & $\$ 39,536.66(-118655.3,39581.97)$ & .617 \\
\hline & & 3 versus 4 & $\$-39,627.89(-667137.9,-543.3532)$ & .045 \\
\hline & & 3 versus 5 & $\$-84,633.25(-166137.9,-3128.597)$ & .038 \\
\hline & & 4 versus 5 & $\$-51,005.36(-128959.5,26948.75)$ & .352 \\
\hline Insurance type & Mean Margin & Insurance Comparison & Difference of Mean $(95 \%$ CI) & $P$ Value \\
\hline Medicaid (1) & $-\$ 6,456.17$ & 1 versus 2 & $\$ 29,502.5(1313.799,57691.2)$ & .036 \\
\hline Medicare (2) & $\$ 23,046.33$ & 1 versus 3 & $\$ 75,244.74$ (43 879.25, 106 610.2) & 0 \\
\hline Worker's compensation ( 3 ) & $\$ 68,788.56$ & 1 versus 4 & $\$ 39,591.16(13052.38,66$ 129.95) & .001 \\
\hline Private insurance (4) & $\$ 33,134.99$ & 1 versus 5 & $\$-16,209.96(-74889.42,42469.5)$ & .933 \\
\hline Charity (5) & $-\$ 22,666.13$ & 2 versus 3 & $\$ 45,742.24(20629.75,70$ 854.73) & 0 \\
\hline \multirow[t]{5}{*}{ Self-pay (6) } & None & 2 versus 4 & $\$ 10,088.66(8650.339,28827.67)$ & .548 \\
\hline & & 2 versus 5 & $\$-45,712.46(-101301.3,9876.411)$ & .152 \\
\hline & & 3 versus 4 & $\$-35,653.57(-58898.82,-12408.33)$ & .001 \\
\hline & & 3 versus 5 & $\$-91,454.7(-148720,-34189.41)$ & \\
\hline & & 4 versus 5 & $\$-55,801.12(-110571.8,-1030.45)$ & .044 \\
\hline
\end{tabular}

Abbreviation: CI, confidence interval.

Medicare $(P=.006)$. Margins were also higher for private insurance than for Medicare $(P<.001)$, and higher for self-pay than for insurance $(P=.020)$ or Medicare $(P=.036)$.

Lastly, for the PLIF group (Table 5), ANOVA demonstrated there was significant variation among insurance type for hospital reimbursements $(P<.001)$. The mean reimbursements from Medicaid, Medicare, worker's compensation, and private insurance were $\$ 13,818.96, \$ 40,171.48$, $\$ 85,268.07$, and $\$ 51,640.18$, respectively. Hospital reimbursement was significantly higher for worker's compensation compared to Medicaid $(P<.001)$, Medicare $(P=.007)$, and private insurance $(P=.045)$. There was also significant variation among insurance types for hospital margins $(P<.001)$. Hospital margins for PLIF with Medicaid, Medicare, worker's compensation, and private insurance were $-\$ 6,456.17, \$ 23,046.33$, $\$ 68,788.56$, and $\$ 33,134.99$, respectively. Medicaid was associated with significantly lower margins than Medicare $(P=.036)$, worker's compensation $(P<.001)$, and private insurance $(P=.001)$. Worker's compensation was associated with significantly higher margins than Medicare $(P<.001)$ and private insurance $(P=.001)$. Hospital margins were significantly lower for self-pay than for worker's compensation $(P<.001)$ or private insurance $(P=.044)$.

\section{DISCUSSION}

DS with associated with spinal stenosis is an extremely common condition in the United States; however, treatment remains controversial. As demonstrated in the SPORT trial, patients with DS treated surgically had substantially greater pain relief and improvement in function compared to patients treated nonoperatively, which has been reflected at 2-, 4-, and 8-year follow-up. ${ }^{4,11}$

Surgical treatment involves laminectomy in order to decompress the neural structures and therefore relieve the symptoms being caused by the compression and irritation. Arthrodesis is then typically performed in order to prevent any further listhesis of the vertebrae. Arthrodesis may also stabilize the degenerative surrounding facet joints and intervertebral discs and therefore provide pain relief. Historically, results have been mixed regarding surgical management and the various fusion methods. ${ }^{12}$ As demonstrated by Herkowitz et al, patients who had concomitant arthrodesis had significant better results with respect to pain relief. ${ }^{13}$ When considering types of arthrodesis, 3 main types are used: PLF, PPS, and PLIF.

While the study by Herkowitz et al demonstrated that patients who were treated with PLF had significantly better results than those treated without fusion, this study did not include those treated with different fusion methods. In a follow-up study in 1997, Fischgrund et al showed that patients who 
had PPS had improved radiographic evidence of fusion rates in comparison to those treated without instrumentation. ${ }^{14}$ However, the clinical and functional outcomes did not differ between these groups. Therefore, this raised the question of whether or not the type of fusion method influences clinical outcomes.

The SPORT results showed that fusion type (PLF, PPS, PLIF) had minimal effect on outcomes and reoperation rates. To this point, SPORT remains one of the largest cohorts of patients with DS with spinal stenosis. Similarly, a systematic review by Campbell et al compared $360^{\circ}$ fusion and PPS in patients with DS. There was no statistically significant difference between the Oswestry disability index and visual analog scale between these groups. ${ }^{15}$ Similarly, a study from 2017 by Challier et al revealed that while there is significant improvement with pain and disability with posterior decompression and instrumented fusion, there was no significant clinical difference between PPS versus PLIF. ${ }^{16}$ Therefore, these studies raise questions as to which types of fusions should be performed, and what the driving forces are behind the decision of which type of fusion method is used. As seen recently, the question regarding when to fuse remains a topic of debate, as the RCT by Försth et al demonstrated that the addition of fusion to decompression surgery did not provide any clinical benefit after 2 years. ${ }^{17}$ Which fusion method to use in the treatment of DS remains incredibly controversial. It still remains unclear as to which patients benefit most from fusions in DS. Ultimately, DS represents a spectrum of disease, and patients with certain characteristics may benefit more from certain fusion methods than others. Altogether, the physician, hospital, insurance, and patient should be aware of the overall costs, expenses, and charges when making these decisions in order to make the most informed decision based on specific characteristics and circumstances.

The results from this study demonstrate that PLFs cost less than instrumented fusions in terms of charges to the primary payer (insurance company or patients), and in terms of expenses that the hospital must pay. Similarly, as more instrumentation is used, the more it costs the primary payer and the hospital; PPS had fewer charges and expenses compared to PLIF. The more we do in terms of fusion method and instrumentation, the more it costs the insurer, the patient, and the hospital.
While implants certainly make up some of the cost difference, there are many other factors outside of implants that factor into overall cost, such as patient characteristics, comorbidities, and length of stay.

Medicare, worker's compensation, and private insurers reimbursed the hospital more than Medicaid for all 3 fusion types. Hospital margins were the lowest for Medicaid. These results reflect what would be expected in terms of payments and margins; worker's compensation and private insurers pay the hospital more than Medicaid or Medicare, and accordingly, the hospital margins increase with worker's compensation and private insurance. Interestingly, the hospital margin for PLF was higher than the instrumented groups for Medicaid, Medicare, and private insurance. In fact, hospital margins were negative for the 2 different instrumented fusion groups for Medicaid patients.

To this point it remains unclear what ultimately is driving the differences in practice with regard to what type of fusion is used. But, what we do know is that the more we do in terms of instrumentation, the more it costs both the hospital and the primary payer. On the contrary, hospital margins actually tended to decrease when more instrumentation was used; hospital margins were greatest in the noninstrumented fusions for the predominant insurance types in our patient population.

As the economic landscape regarding spine surgery continues to change, there needs to be better alignment with incentives for all parties involved, especially with the possibility of bundled payments. Recent work has revealed that hospitals tend to have higher charges and reimbursements relative to the charges and reimbursements of surgeons. Hospitals receive more in reimbursement for complex cases and patients; however, this is not reflected proportionally in surgeon reimbursements. ${ }^{18}$ This raises concerns moving forward, as it may result in providers operating on healthier, less-complex patients, and therefore moving away from sicker patients needing complex procedures. In order to create a more efficient, cost-effective system, the primary stakeholders (patients, surgeons, hospitals, third-party payers) must have a better understanding of the true charges, costs, margins, and reimbursements. ${ }^{19}$

There are some limitations to this analysis. As it was a retrospective review with corresponding economic audit and analysis, the accuracy depended 
on coding practices over the course of multiple years. We were also unable to collect patient-level data including degree of slip, degree of stenosis, and how this corresponded with fusion method. Furthermore, length of stay, and then any further associated hospital charges and costs were those of patient's entire admission; this may reflect additional postoperative or medical complications that were not captured within our review. Lastly, the data were not stratified based upon attending surgeon and level of assistant, which can certainly have an effect regarding intraoperative time, or even surgeon preference of fusion method.

\section{REFERENCES}

1. Hu SS, Tribus CB, Diab M, et al. Spondylolisthesis and spondylolysis. J Bone Joint Surg Am. 2008;90(3):656-671.

2. Weinstein JN, Lurie JD, Tosteson TD, et al. Surgical versus nonsurgical treatment for lumbar degenerative spondylolisthesis. $N$ Engl J Med. 2007;356(22):2257-2270.

3. Abdu WA, Lurie JD, Spratt KF, et al. Degenerative spondylolisthesis: does fusion method influence outcome? Fouryear results of the spine patient outcomes research trial. Spine (Phila Pa 1976). 2009;34(21):2351-2360.

4. Abdu WA, Sacks OA, Tosteson ANA, et al. Long-term results of surgery compared with nonoperative treatment for lumbar degenerative spondylolisthesis in the spine outcomes research trial (SPORT). Spine (Phila Pa 1976). 2018;43(23);1619-1630.

5. Rajaee SS, Bae HW, Kanim LE, et al. Spinal fusion in the United States: analysis of trends from 1998 to 2008. Spine (Phila Pa 1976). 2012;37(1):67-76.

6. Weinstein JN, Lurie JD, Olson PR, et al. United States' trends and regional variations in lumbar spine surgery: 19922003. Spine (Phila Pa 1976). 2006;31(23):2707-2714.

7. McGuire KJ, Harrast J, Herkowitz H, Weinstein JN. Geographic variation in the surgical treatment of degenerative cervical disc disease: American Board of Orthopedic Surgery (ABOS) quality improvement initiative; part II candidates. Spine (Phila Pa 1976). 2012;37(1):57-66.

8. Cosgrove JC. Medicare: lack of price transparency may hamper hospitals' ability to be prudent purchasers of implantable medical devices. 2012. http://www.gao.gov/products/ GAO-12-126. Accessed April 17, 2018.

9. AGawande Gawande A. The cost conundrum: what a town in Texas can tell us about health care. New Yorker. June 1 2009. http://www.newyorker.com/reporting/2009/06/01/ 090601fa_fact_gawande. Accessed April 17, 2018.

10. Carragee EJ. The increasing morbidity of elective spinal stenosis surgery: is it necessary? JAMA. 2010;303(13):13091310 .

11. Weinstein JN, Lurie JD, Tosteson TD, et al. Surgical compared with nonoperative treatment for lumbar degenerative spondylolisthesis. Four-year results in the spine patient outcomes research trial (SPORT) randomized and observational cohorts. J Bone Joint Surg Am. 2010;91(6):1295-1304.

12. Gerling MC, Leven D, Passias PG, et al. Risks factors for reoperation in patients treated surgically for degenerative spondylolisthesis: a subanalysis of the 8 year data from the SPORT trial. Spine (Phila Pa 1976). 2017;41(10):901-909.

13. Herkowitz HN, Kurz LT. Degenerative lumbar spondylolisthesis with spinal stenosis. A prospective study comparing decompression with decompression and intertransverse process arthrodesis. J Bone Joint Surg Am. 1991;73(5):802-808.

14. Fischgrund JS, Mackay M, Herkowitz HN, et al. 1997 Volvo Award winner in clinical studies. Degenerative lumbar spondylolisthesis with spinal stenosis: a prospective, randomized study comparing decompressive laminectomy and arthrodesis with and without spinal instrumentation. Spine (Phila Pa 1976). 1997;22(24):2807-2812.

15. Campbell RC, Mobbs RJ, Lu VM, et al. Posterolateral fusion versus interbody fusion for degenerative spondylolisthesis: systematic review and meta-analysis. Global Spine $J$. 2017;7(23):482-490.

16. Challier V, Boissiere L, Obeid I, et al. One-level lumbar degenerative spondylolisthesis and posterior approach: is transforaminal lateral interbody fusion mandatory? A randomized controlled trial with 2-year follow-up. Spine (Phila Pa 1976). 2017;42(8):531-539.

17. Försth P, Ólafsson G, Carlsson T, et al. A randomized, controlled trial of fusion surgery for lumbar spinal stenosis. $N$ Engl J Med. 2016; 374(15):1413-1423.

18. Jain N, Phillips F, Shimer A, Khan S. Surgeon reimbursement relative to hospital payments for spinal fusion. Spine (Phila Pa 1976). 2018;43(10):720-731.

19. Virk S, Philips F, Moffat-Bruce S, Khan S. What factors influence reimbursement for 1-2 level anterior discectomy and fusion (ACDF) procedures? Spine (Phila Pa 1976). 2019;44(1):E33-E38.

Disclosures and COl: Dartmouth College Institutional Review Board Approval, CPHS no. 00024098.

Corresponding Author: Keith Lyons, MD, Dartmouth-Hitchcock Medical Center, Department of Orthopaedics, One Medical Center Dr, Lebanon, NH 03766. Phone: (774) 239-4895; Fax: (603) 6505338; Email: keith.w.lyons@hitchcock.org.

Published 31 August 2019

This manuscript is generously published free of charge by ISASS, the International Society for the Advancement of Spine Surgery. Copyright (C) 2019 ISASS. To see more or order reprints or permissions, see http://ijssurgery.com. 